Case Report

\title{
Varicella Zoster Virus Meningitis in a Young Immunocompetent Adult without Rash: A Misleading Clinical Presentation
}

\author{
Thomas Pasedag, ${ }^{1,2}$ Karin Weissenborn, ${ }^{1}$ Ulrich Wurster, ${ }^{1}$ Tina Ganzenmueller, ${ }^{3}$ \\ Martin Stangel, ${ }^{1}$ and Thomas Skripuletz ${ }^{1}$ \\ ${ }^{1}$ Department of Neurology, Hannover Medical School, Carl-Neuberg-Straße 1, 30625 Hannover, Germany \\ ${ }^{2}$ Department of Psychiatry and Psychotherapy, Klinikum Region Hannover, Rohdehof 3, Langenhagen, Germany \\ ${ }^{3}$ Institute of Virology, Hannover Medical School, Carl-Neuberg-Straße 1, 30625 Hannover, Germany \\ Correspondence should be addressed to Thomas Skripuletz; skripuletz.thomas@mh-hannover.de
}

Received 1 October 2014; Revised 10 December 2014; Accepted 14 December 2014; Published 29 December 2014

Academic Editor: Dominic B. Fee

Copyright (C) 2014 Thomas Pasedag et al. This is an open access article distributed under the Creative Commons Attribution License, which permits unrestricted use, distribution, and reproduction in any medium, provided the original work is properly cited.

Meningitis caused by varicella zoster virus (VZV) is rare in healthy population. Predominantly immunocompromised patients are affected by reactivation of this virus with primary clinical features of rash and neurological symptoms. Here we report a young otherwise healthy man diagnosed with a VZV meningitis without rash. He complained of acute headache, nausea, and vomiting. The clinical examination did not show any neurological deficits or rash. Cerebrospinal fluid (CSF) analysis revealed a high leukocyte cell count of 1720 cells $/ \mu \mathrm{L}$ and an elevated total protein of $1460 \mathrm{mg} / \mathrm{L}$ misleadingly indicating a bacterial infection. Further CSF analyses, including polymerase chain reaction (PCR) and detection of intrathecal synthesis of antibodies, showed a VZV infection. Clinical and CSF follow-up examinations proved the successful antiviral treatment. In conclusion, even young immunocompetent patients without rash might present with VZV meningitis. CSF examination is a key procedure in the diagnosis of CNS infections but in rare cases the standard values cell count and total protein might misleadingly indicate a bacterial infection. Thus, virological analyses should be considered even when a bacterial infection is suspected.

\section{Introduction}

Infections with neurotropic herpes viruses (herpes simplex type $1 / 2$, varicella zoster virus (VZV)) are frequent in humans. These viruses persist within cranial nerves, dorsal roots, and autonomic ganglia causing latent infections with the ability of reactivation [1-3]. Reactivation of VZV shows mainly a herpes zoster presenting with rash and pain affecting the entire dermatome and less frequently a zoster sine herpete [1-3]. VZV infection of the central nervous system (CNS) such as encephalitis, meningitis, myelitis, or angiitis occurs less frequently but is feared because of the numerous unfavourable outcomes $[1,3,4]$. Usually CNS infection with VZV comes along with dermal affection but can rarely develop without rash $[1,3,5-10]$.

Acute infection or VZV reactivation affects predominantly older individuals and/or immunocompromised patients $[1-3,9]$. CNS infection with VZV in young healthy adults is rare and is unexpected and only very few cases have been described so far [5-9]. Here, we describe a young previously healthy man with VZV meningitis who had only minimal symptoms.

\section{Case Presentation}

An 18-year-old man experienced severe occipital headache accompanied by nausea and vomiting. All symptoms started immediately after a backward roll doing judo exercise. Treatment with paracetamol, acetylsalicylic acid, and metamizole did not show beneficial effects. Thus, he presented to our emergency room nine days after the first symptoms.

The physical examination was normal. Particularly, stiff neck as a typical sign of meningitis was not found and he did not show any rash. He had never been sick before and did not take any medications regularly. Furthermore, he did not smoke or drink alcohol excessively. 


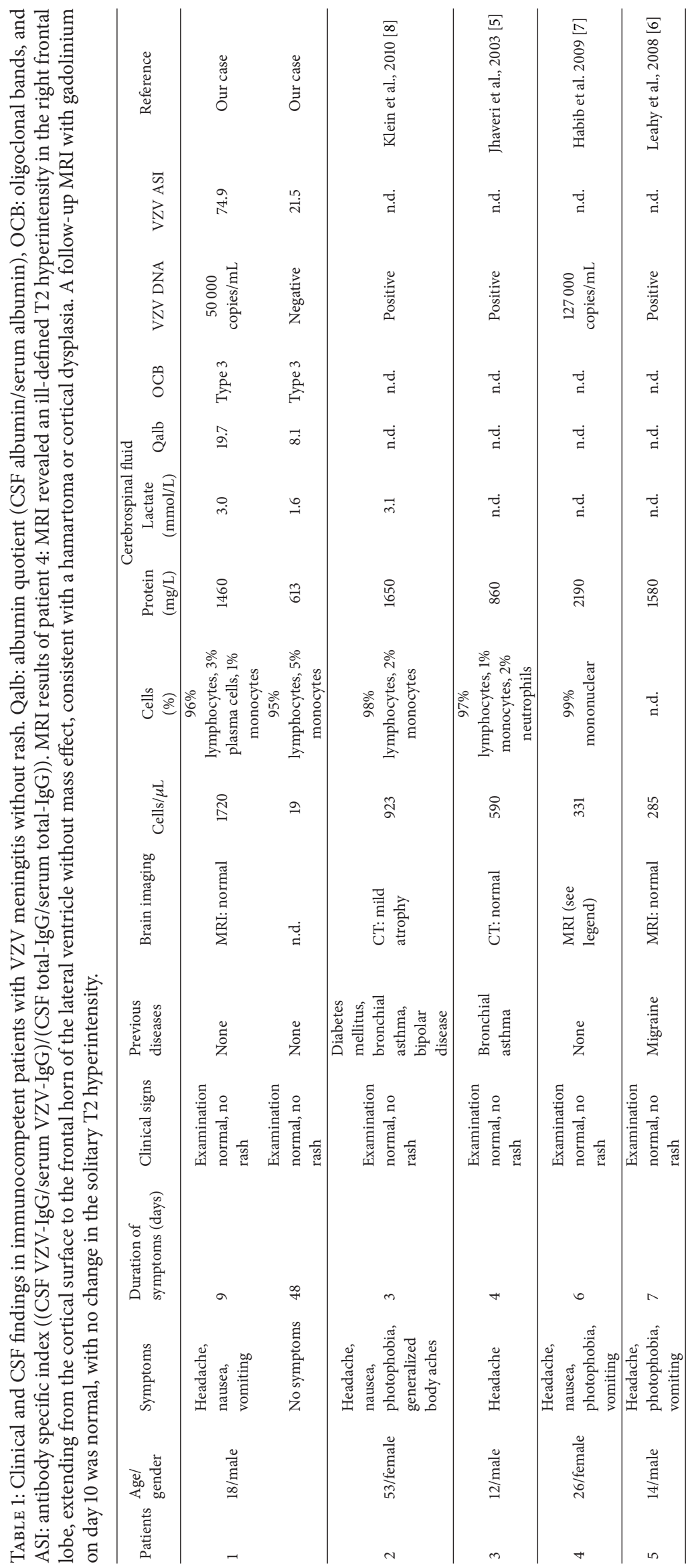


Subarachnoid hemorrhage or dissection of cerebral arteries was first considered. Magnetic resonance imaging (MRI) scan of the brain showed no abnormalities such as bleeding, infarction, or malignancy. Additional MR-angiography and ultrasound examination of carotid, vertebral, and intracranial arteries revealed no vascular alterations. Measurements of body temperature and blood pressure as well as laboratory urine and blood examinations (blood count, sodium, potassium, C-reactive protein, creatinine, transaminases, creatinine kinase, serum protein electrophoresis, thyroid-stimulating hormone, thyroxine, triiodothyronine, anti-thyroid autoantibodies (anti-thyroid peroxidase antibodies, thyrotropin receptor antibodies, and thyroglobulin antibodies), anti-nuclear antibodies, anti-neutrophil cytoplasmic antibodies, anti-cardiolipin antibodies, angiotensinconverting enzyme, and amount of vitamins B12, B6, and B1) showed normal results.

CSF analysis revealed a high leukocyte cell count of 1720 cells $/ \mu \mathrm{L}$ and an elevated total CSF protein of $1460 \mathrm{mg} / \mathrm{L}$. Furthermore, slightly elevated CSF lactate concentration of $3.0 \mathrm{mmol} / \mathrm{L}$ and a slightly reduced CSF glucose concentration of $42 \mathrm{mg} / \mathrm{dL}$ were found. Considering a bacterial infection, intravenous treatment with ceftriaxone $(2 \mathrm{~g} /$ day $)$ and ampicillin ( $15 \mathrm{~g} /$ day) was applied.

Cytologic analysis of the CSF revealed 3\% plasma cells. The remaining cells were predominantly lymphocytes with normal morphology. Further CSF abnormalities included elevated albumin quotient (QAlb) indicating a moderate bloodCSF-barrier-dysfunction (Table 1). Intrathecal immunoglobulin (Ig) synthesis of $\operatorname{IgG}, \operatorname{IgM}$, and $\operatorname{Ig} A$ as calculated based on the method of Reiber-Felgenhauer [11] was not found. Oligoclonal bands restricted to the CSF were identified indicating intrathecal IgG synthesis in the CSF. Furthermore, identical oligoclonal IgG bands in CSF and serum were found indicating a systemic humoral immune response towards foreign antigens and/or self-antigens.

Microbiological analyses did not detect any bacterial infection. Further analyses for Borrelia burgdorferi, Treponema pallidum, Mycobacterium tuberculosis, toxoplasmosis, Candida, and Cryptococcus neoformans showed negative results. Virological examinations presented negative results for herpes simplex virus, cytomegalovirus, Epstein-Barr virus, enteroviruses, tick-borne encephalitis, human immunodeficiency virus, and hepatitides B, C, and A. Quantitative real-time PCR analysis [12] of the CSF revealed presence of VZV-DNA with a concentration of 50.000 copies $/ \mathrm{mL}$ indicating high viral replication. Thus, one day after antibiotic therapy the patient was treated with acyclovir $(2250 \mathrm{mg} /$ day intravenously for 11 days), followed by valacyclovir $(3000 \mathrm{mg} /$ day orally for 5 days). Additionally, we measured the intrathecal synthesis [13] of VZV immunoglobulin G antibodies (Enzygnost Anti-VZV/IgG, Siemens Healthcare Diagnostics) and found a specific antibody index (AI) of 74.9 (normal value $<1.5$ ). The presence of a strong intrathecal IgG production against VZV confirmed the VZV infection in the CNS.

Eleven days after intravenous therapy, the patient was discharged feeling well. Follow-up CSF examination was performed 23 days after the end of antiviral treatment. A slight pleocytosis with 19 cells $/ \mu \mathrm{L}$ was still found. Plasma cells were not found and lymphocytes and monocytes showed normal morphology. VZV-PCR was negative but a persisting intrathecal IgG production to VZV (specific antibody index of 21.5) indicated a preceding VZV infection. The patient felt well without any symptoms. He practiced judo again four times per week.

\section{Discussion}

Here we present a young previously healthy man with a VZV meningitis without rash. This case is extraordinary because the clinical presentation was unusual for a patient with meningitis and the initial CSF findings with very high pleocytosis and elevated total CSF protein initially misleadingly suggested a bacterial infection. Interestingly, further CSF examinations detected a VZV infection.

Our case underlines the importance of specialised CSF diagnostics in acute neurological emergency situations. CSF examination is generally considered a key procedure in the diagnosis of CNS infections [14]. Using sensitive laboratory analyses (e.g., PCR and detection of intrathecal production of specific antibodies) recent epidemiological studies found a portion of $5-29 \%$ of VZV in aseptic meningitis and encephalitis and it was suspected that VZV infections had been underestimated in earlier publications [9, 15-18]. Nevertheless in immunocompetent patients without rash and neurological deficits (as in our case) VZV meningitis seems to be rare and only few cases have been described to date (see Table 1). Infections of the CNS are accompanied by an elevated cell count in the CSF. In large series including patients with aseptic meningitis and encephalitis CSF findings predominantly revealed lymphomonocytic pleocytosis of less than 500 cells $/ \mu \mathrm{L}$, mild to moderately elevated total protein, and normal lactate levels [16-18]. In patients with VZV infection median cell counts of $43 / \mu \mathrm{L}, 132 / \mu \mathrm{L}, 286 / \mu \mathrm{L}$, and $293 / \mu \mathrm{L}$ were found and the cell counts ranged from 15 to 840 cells $/ \mu \mathrm{L}[9,16-18]$. In our case, we found the highest pleocytosis $(1720$ cells $/ \mu \mathrm{L})$ that has been described for this group of patients. In addition, total protein and lactate concentration were elevated leading to a misleading diagnosis of bacterial meningitis.

In conclusion, even young and previously healthy patients without clinical features of dermal irritation such as rash might present with VZV meningitis. We highlight the importance of considering VZV as a possible cause for meningitis even in previously healthy young patients and the recommended diagnostic lumbar puncture. Detailed CSF diagnostic procedures including PCR and detection of intrathecal synthesis of antiviral antibodies (especially for VZV and HSV) should be considered even though CSF cell count and total protein seem to indicate a bacterial infection.

\section{Conflict of Interests}

The authors declare that there is no conflict of interests regarding the publication of this paper. 


\section{References}

[1] D. H. Gilden, B. K. Kleinschmidt-DeMasters, J. J. LaGuardia, R. Mahalingam, and R. J. Cohrs, "Neurologic complications of the reactivation of varicella-zoster virus," The New England Journal of Medicine, vol. 342, no. 9, pp. 635-645, 2000.

[2] I. Steiner, P. G. Kennedy, and A. R. Pachner, "The neurotropic herpes viruses: herpes simplex and varicella-zoster," The Lancet Neurology, vol. 6, no. 11, pp. 1015-1028, 2007.

[3] N. H. Mueller, D. H. Gilden, R. J. Cohrs, R. Mahalingam, and M. A. Nagel, "Varicella zoster virus infection: clinical features, molecular pathogenesis of disease, and latency," Neurologic Clinics, vol. 26, no. 3, pp. 675-697, 2008.

[4] D. Gilden, R. J. Cohrs, R. Mahalingam, and M. A. Nagel, "Varicella zoster virus vasculopathies: diverse clinical manifestations, laboratory features, pathogenesis, and treatment," The Lancet Neurology, vol. 8, no. 8, pp. 731-740, 2009.

[5] R. Jhaveri, R. Sankar, S. Yazdani, and J. D. Cherry, "Varicellazoster virus: an overlooked cause of aseptic meningitis," Pediatric Infectious Disease Journal, vol. 22, no. 1, pp. 96-97, 2003.

[6] T. R. Leahy, D. W. M. Webb, H. Hoey, and K. M. Butler, "Varicella zoster virus associated acute aseptic meningitis without exanthem in an immunocompetent 14-year-old boy," Pediatric Infectious Disease Journal, vol. 27, no. 4, pp. 362-363, 2008.

[7] A. A. Habib, D. Gilden, D. S. Schmid, and J. Safdieh, "Varicella zoster virus meningitis with hypoglycorrhachia in the absence of rash in an immunocompetent woman," Journal of NeuroVirology, vol. 15, no. 2, pp. 206-208, 2009.

[8] N. C. Klein, B. McDermott, and B. A. Cunha, "Varicella-zoster virus meningoencephalitis in an immunocompetent patient without a rash," Scandinavian Journal of Infectious Diseases, vol. 42, no. 8, pp. 631-633, 2010.

[9] A. Douglas, P. Harris, F. Francis, and R. Norton, "Herpes zoster meningoencephalitis: not only a disease of the immunocompromised?" Infection, vol. 38, no. 1, pp. 73-75, 2010.

[10] K. Lynch, P. Agarwal, A. Paranandi, S. Hadley, and M. Vullaganti, "Extensive VZV encephalomyelitis without rash in an elderly man," Case Reports in Neurological Medicine, vol. 2014, Article ID 694750, 5 pages, 2014.

[11] H. Reiber and J. B. Peter, "Cerebrospinal fluid analysis: diseaserelated data patterns and evaluation programs," Journal of the Neurological Sciences, vol. 184, no. 2, pp. 101-122, 2001.

[12] I. Engelmann, D. R. Petzold, A. Kosinska, B. G. Hepkema, T. F. Schulz, and A. Heim, "Rapid quantitative PCR assays for the simultaneous detection of herpes simplex virus, varicella zoster virus, cytomegalovirus, Epstein-Barr virus, and human herpesvirus 6 DNA in blood and other clinical specimens," Journal of Medical Virology, vol. 80, no. 3, pp. 467-477, 2008.

[13] H. Reiber and P. Lange, "Quantification of virus-specific antibodies in cerebrospinal fluid and serum: sensitive and specific detection of antibody synthesis in brain," Clinical Chemistry, vol. 37, no. 7, pp. 1153-1160, 1991.

[14] T. Skripuletz, P. Schwenkenbecher, K. Pars et al., "Importance of follow-up cerebrospinal fluid analysis in cryptococcal meningoencephalitis," Disease Markers, vol. 2014, Article ID 162576, 10 pages, 2014.

[15] M. Koskiniemi, T. Rantalaiho, H. Piiparinen et al., "Infections of the central nervous system of suspected viral origin: a collaborative study from Finland," Journal of NeuroVirology, vol. 7, no. 5, pp. 400-408, 2001.

[16] D. A. Nowak, R. Boehmer, and H.-H. Fuchs, "A retrospective clinical, laboratory and outcome analysis in 43 cases of acute aseptic meningitis," European Journal of Neurology, vol. 10, no. 3, pp. 271-280, 2003.

[17] L. Kupila, T. Vuorinen, R. Vainionpää, V. Hukkanen, R. J. Marttila, and P. Kotilainen, "Etiology of aseptic meningitis and encephalitis in an adult population," Neurology, vol. 66, no. 1, pp. 75-80, 2006.

[18] F. Frantzidou, F. Kamaria, K. Dumaidi, L. Skoura, A. Antoniadis, and A. Papa, "Aseptic meningitis and encephalitis because of herpesviruses and enteroviruses in an immunocompetent adult population," European Journal of Neurology, vol. 15, no. 9, pp. 995-997, 2008. 


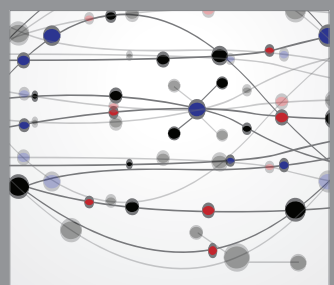

The Scientific World Journal
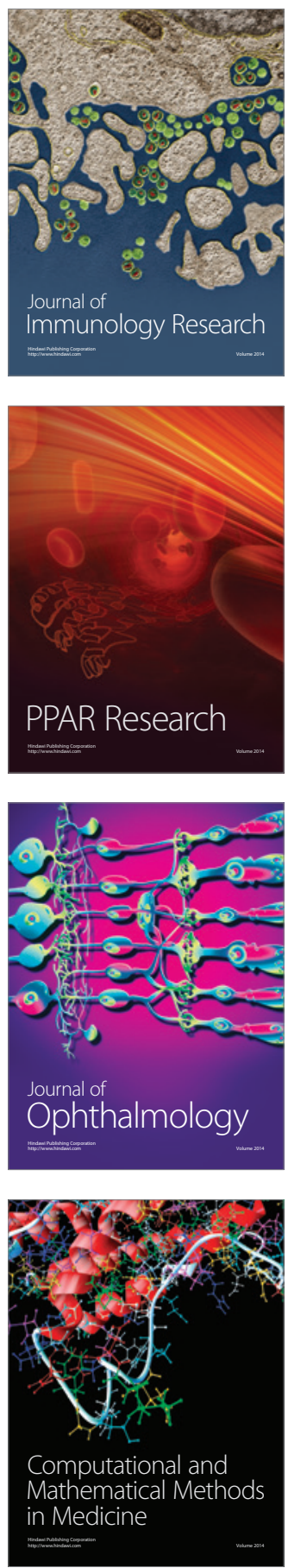

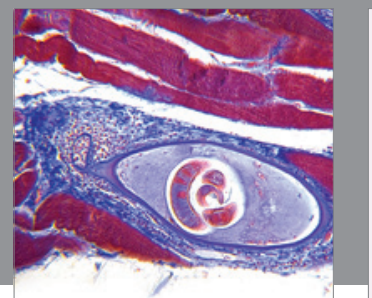

Gastroenterology

Research and Practice
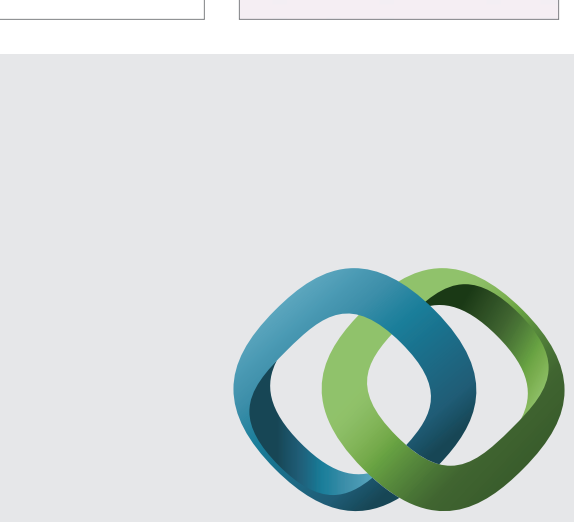

\section{Hindawi}

Submit your manuscripts at

http://www.hindawi.com
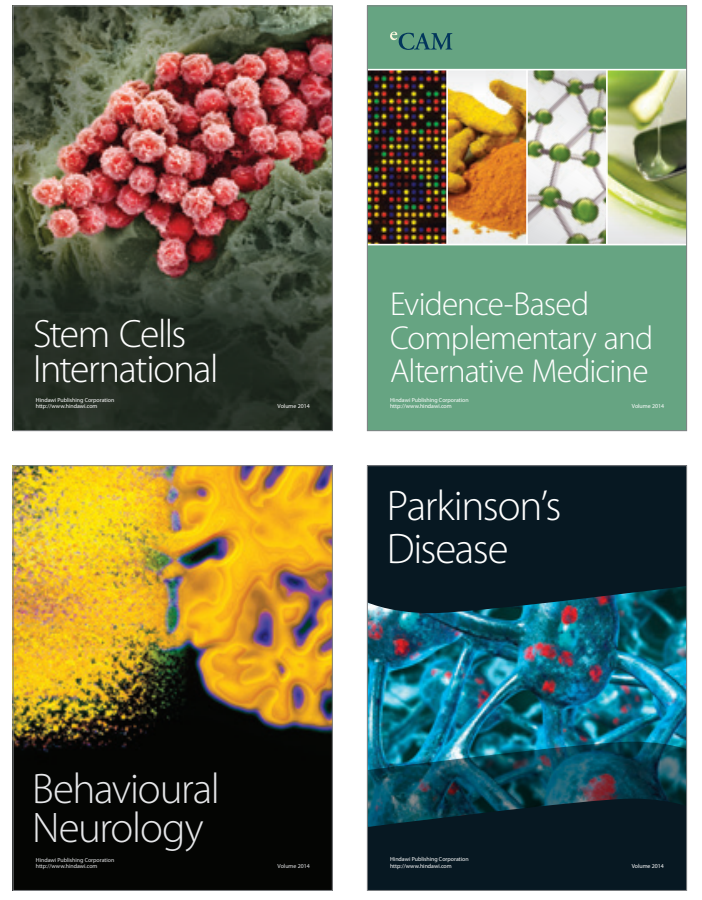
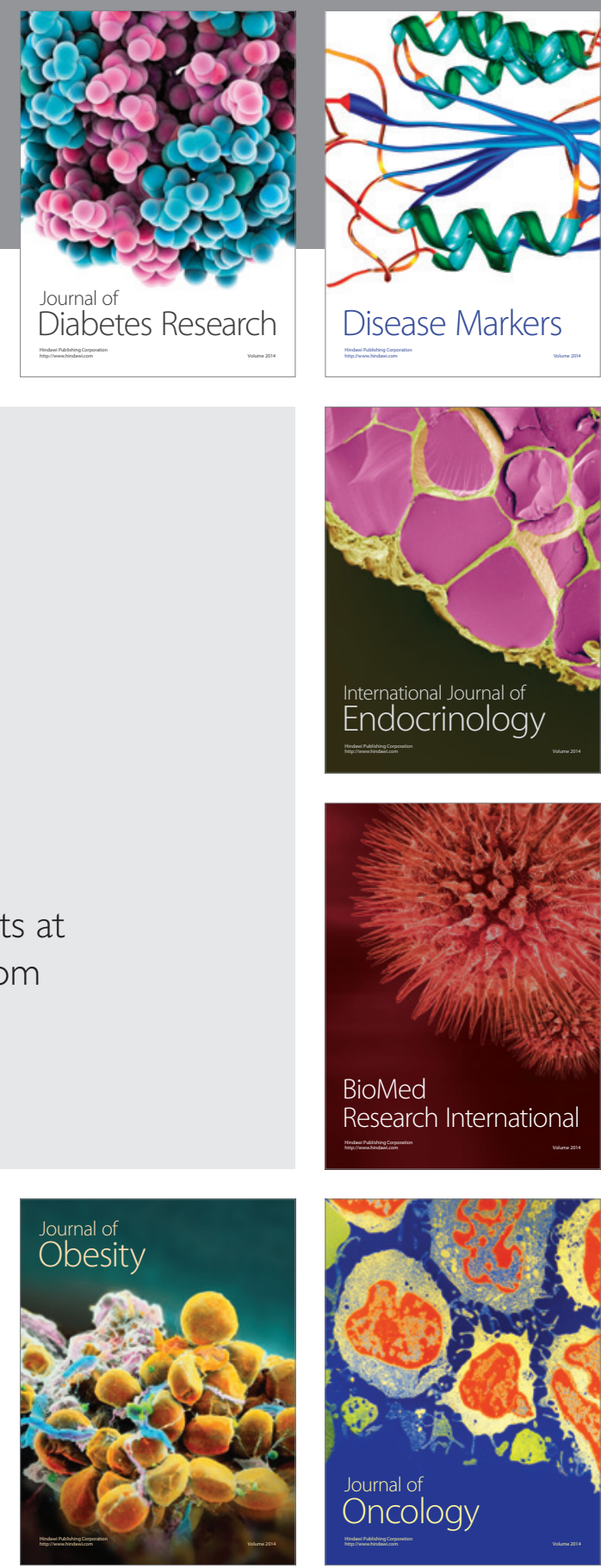

Disease Markers
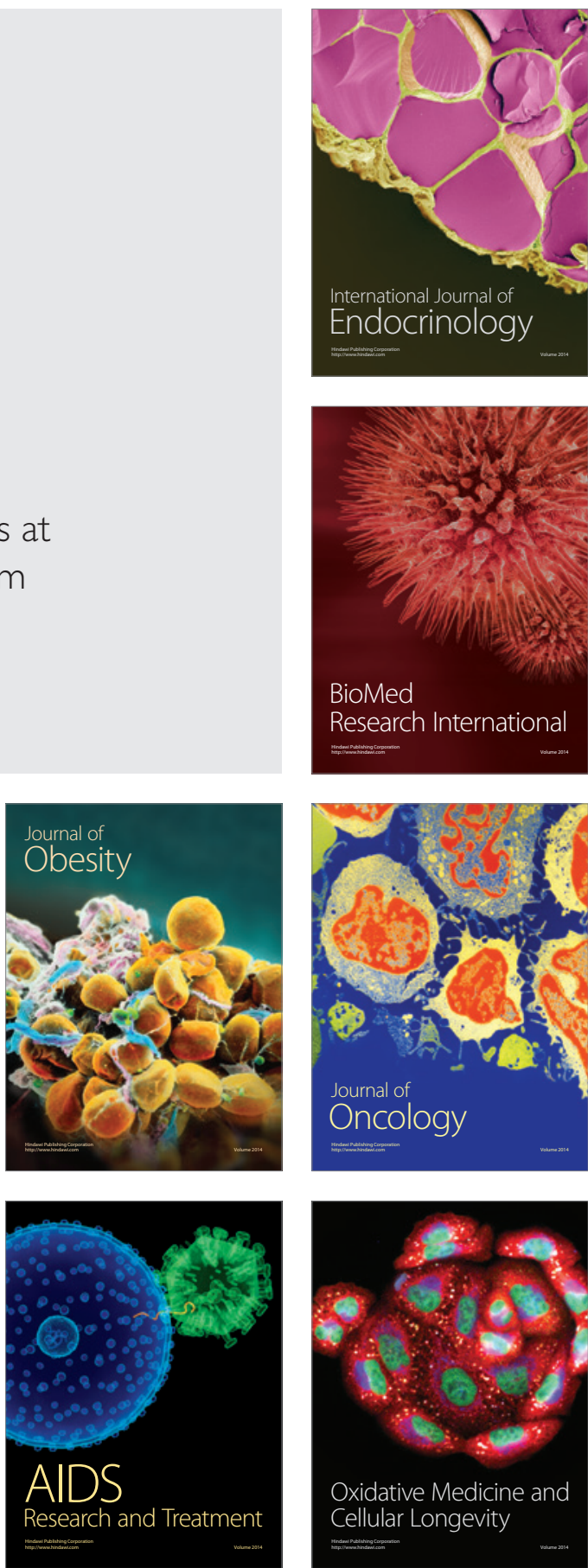